\title{
Metabolomic evaluation of pulsed electric field-induced stress on potato tissue
}

\author{
Federico Gómez Galindo • Petr Dejmek • \\ Krister Lundgren · Allan G. Rasmusson • \\ António Vicente $\cdot$ Thomas Moritz
}

Received: 25 February 2009 / Accepted: 6 May 2009 / Published online: 4 June 2009

(C) Springer-Verlag 2009

\begin{abstract}
Metabolite profiling was used to characterize stress responses of potato tissue subjected to reversible electroporation, providing insights on how potato tissue responds to a physical stimulus such as pulsed electric fields (PEF), which is an artificial stress. Wounded potato tissue was subjected to field strengths ranging from 200 to $400 \mathrm{~V} / \mathrm{cm}$, with a single rectangular pulse of $1 \mathrm{~ms}$. Electroporation was demonstrated by propidium iodide staining of the cell nucleae. Metabolic profiling of data obtained through GC/TOF-MS and UPLC/TOF-MS complemented with orthogonal projections to latent structures clustering analysis showed that $24 \mathrm{~h}$ after the application of PEF, potato metabolism shows PEF-specific responses characterized by the changes in the hexose pool that may involve starch and ascorbic acid degradation.
\end{abstract}

F. G. Galindo $(\bowtie) \cdot$ A. Vicente

Centro de Engenharia Biológica,

Institute for Biotechnology and Bioengineering (IBB),

Universidade do Minho, Campus de Gualtar,

4710-057 Braga, Portugal

e-mail: Federico.Gomez@food.lth.se

P. Dejmek

Department of Food Technology Engineering and Nutrition,

Lund University, 124, 22100 Lund, Sweden

K. Lundgren · T. Moritz

Department of Forest Genetics and Plant Physiology,

Umeå Plant Science Center, Swedish University of Agricultural

Sciences, 90187 Umeå, Sweden

A. G. Rasmusson

Department of Cell and Organism Biology,

Lund University, Sölvegatan 35B, 22362 Lund, Sweden
Keywords Cell membrane recovery · Electroporation . Metabolic analysis - OPLS multivariate data analysis . Stress response $\cdot$ Wounding

\begin{tabular}{|c|c|}
\hline \multicolumn{2}{|l|}{ Abbreviations } \\
\hline $\mathrm{ACN}$ & Acetonitrile \\
\hline DRE & Dynamic range enhancement \\
\hline GC/TOF-MS & $\begin{array}{l}\text { Gas chromatography/time-of-flight } \\
\text { mass spectrometry }\end{array}$ \\
\hline H-MCR & Hierarchical multivariate curve resolution \\
\hline MST & Mass spectral tag \\
\hline MSTFA & $\begin{array}{l}N \text {-Methyl- } N \text {-(trimethylsilyl)trifluoroace- } \\
\text { tamide }\end{array}$ \\
\hline NIST & $\begin{array}{l}\text { National Institute of Standards and } \\
\text { Technology }\end{array}$ \\
\hline OPLS & Orthogonal projections to latent structures \\
\hline PEF & Pulsed electric field \\
\hline RI & Retention index \\
\hline UPLC/TOF-MS & $\begin{array}{l}\text { Ultra performance liquid chromatogra- } \\
\text { phy/time-of-flight mass spectrometry }\end{array}$ \\
\hline
\end{tabular}

Introduction

In recent years, there has been an increasing interest in the use of pulsed electric field (PEF) technology due to its potential to induce non-thermal permeabilization of cell membranes. The external application of an electric field $(\leq 1 \mathrm{KV} / \mathrm{cm})$ induces a potential difference of $\sim 0.3-1 \mathrm{~V}$ across the cytoplasmic membrane for a period long enough (microseconds to milliseconds) to induce pore formation in the plasma membrane (Weaver 2000). Depending on the cell properties (i.e. size, conductivity, shape and orientation) and electropulsation parameters (i.e. field strength, duration and number of pulses), the application of PEF may 
cause lethal damage to cells due to irreversible loss of cell membrane permeability properties, leakage of cytoplasmic contents and lysis (Aronsson et al. 2001).

By strict control of the electropulsation parameters, permeabilization may evade affecting the cell viability. In this non-lethal version of the PEF technique, physiological responses to PEF-induced stress are still largely unknown. It has been reported that PEF affects metabolism including an oxidative burst with the consequent generation of reactive oxygen species (ROS) (Gabriel and Teissié 1994; Sabri et al. 1996), which is a common response to stress (Gómez Galindo et al. 2007). ROS have been suggested to be part of the endogenous signal components required for elicitorinduced synthesis of secondary metabolites (Baker and Orlandi 1995), which are widely believed to be part of the defense response of plants to stress (Shohael et al. 2006). When using PEF as stressor, interesting findings for the pharmaceutical field, such as the increased yields of a cytostatic compound in cell culture of Taxus chinensis (Ye et al. 2004), and for the food science and nutrition field, such as the increased concentration of antioxidants and phytoesterols from oil seeds and fruits (Guderjan et al. 2005, 2007; Balasa 2007), encourage deeper metabolic studies that can help to a better understanding of the complex, dynamic metabolic behavior of plant tissues subjected to this novel (i.e. not present in nature) stress condition.

Metabolic profiling, which refers to the non-biased, comprehensive analysis of soluble cellular metabolites from a biological system (Dunn et al. 2005) has been applied to the study of plant metabolism over the past several years (Wishart 2008). Metabolic profiling in plant systems has been used, among other applications, to fingerprint species, genotypes or ecotypes for taxonomic or biochemical purposes (Huhman and Sumner 2002; Beckmann et al. 2007), characterize food components (Mattivi et al. 2006; Moco et al. 2006; Pereira et al. 2006; $\mathrm{Hu}$ et al. 2007), study developmental processes (Roessner et al. 2003; Jeong et al. 2004) and monitor changes in metabolites in relation to exogenous stimuli (Kaplan et al. 2004, 2007; Rizhsky et al. 2004; Gray and Heath 2005; Yang and Bernards 2007). Global metabolic profiling analysis holds the promise to permit simultaneous monitoring of precursors, intermediates and products of metabolic pathways. It is a research tool that can detect and monitor unidentified compounds as well as identified metabolites that play important roles in metabolism and physiology (Kaplan et al. 2004) and, in the context of this work, responses to stress.

We have performed metabolic profiling analysis using gas chromatography-mass spectrometry/time-offlight (GC/TOF-MS), complemented with a targeted analysis of specific metabolites using ultra performance liquid chromatography-mass spectrometry/time-of-flight (UPLC/
TOF-MS) aiming at identifying compounds that exhibit PEF-specific responses when the electric pulses are applied to cause electroporation to the wounded potato tissue. This study allows discriminating between the potatoes response to PEF treatment against that of wounding alone, giving insights on to what extent PEF overlaps with other stresses. We suggest here that PEFs may cause effects in the metabolome of potato, which might be linked with cellular events following electroporation and recovery of cell membrane functionality.

\section{Materials and methods}

\section{Raw material, handling and storage}

Potato tubers (Solanum tuberosum L. cv. Bintje) grown in the south of Sweden were used. The potatoes were harvested and placed in a storage room, forming piles of $4.5 \mathrm{~m}$ maximum height. The potatoes were stored at $4{ }^{\circ} \mathrm{C}$ and approximately $100 \% \mathrm{RH}$ in the dark without the addition of sprouting inhibitors. These are conditions routinely practised by the producer (Lantmännen Solanum AB, Kävlinge, Sweden). Potato tubers free from defects, stored under the described conditions for 3 months, were selected at the farm storage facility and transported to our laboratory in plastic bags kept in insulated boxes on ice. The potatoes were then placed in a closed refrigerated chamber for 1 week at $4^{\circ} \mathrm{C}$ and with a water vapor saturated atmosphere in darkness until used.

\section{Preparation of samples}

Medium-sized potato tubers $(13.0 \pm 3.0 \mathrm{~cm}$ in length, $7.0 \pm 0.5 \mathrm{~cm}$ diameter) were manually washed and peeled. Slices, $15-\mathrm{mm}$ thick were cut from the center of a single tuber. The slices were oriented perpendicular to the major tuber axis. Rectangular cross-section samples, $15 \mathrm{~mm}$ long and $6.0 \mathrm{~mm}$ wide, were obtained from the phloem parenchyma tissue of the slices using a pair of parallel sharp blades. Immediately after cutting, the sample was rinsed with distilled water (at $20^{\circ} \mathrm{C}$ ) and gently blotted with medical wipes to remove the excess of water from the sample surface.

Electrical treatments and measurement of the tissue electrical responses

Electric pulses were delivered to the rectangular samples through two parallel, flat stainless steel electrodes $(35 \mathrm{~mm}$ long and $10 \mathrm{~mm}$ wide) separated $6 \mathrm{~mm}$. Electric pulses were delivered axially to the tissue using a Cellect electromanipulation instrument (BioFusion SCI AB, Lund, 
Sweden). Samples were treated at varying voltages (120, 180,240 and $300 \mathrm{~V}$, which corresponds to the electric field strength in air of 200,300, 400 and $500 \mathrm{~V} / \mathrm{cm}$ ) with $1 \mathrm{~ms}$ rectangular pulses.

The resistance of the tissue samples during the pulsing period was measured as the potential difference over a reference resistor ( $300 \Omega$ ) connected in series to the pulse generator. Samples resistance was stored and observed on a digital storage oscilloscope (EM621 digital oscilloscope, ETC. instruments, Zilina, Slovak Republic) connected to the system. At the last part of the pulse period, the currenttime relationship was converted into the "instantaneous" resistance by dividing the applied voltage by the timedependent current, $V / I(t)$. The resistance of the tissue was then evaluated by subtracting the reference resistance.

Sample impedance (electrical resistance of the intact tissue) was measured prior to pulsing, 6 and $24 \mathrm{~h}$ after pulsing by using a low-voltage sinusoidal wave form at $5 \mathrm{~V}$ and $1 \mathrm{kHz}$, as described by Chalermchat (2005). The wave form was generated by a function generator (PC function generator, K8016, Velleman instruments, Gavere, Belgium). A constant resistor of $300 \Omega$ was connected in series in the circuit between the samples and the function generator in order to monitor the responding voltage of the whole system. The responding voltage was monitored and recorded by the digital oscilloscope. Four measurements were done for each PEF condition.

Evaluation of the electrical treatments by fluorescence microscopy

The effect of electrical treatments on cell membrane electroporation was tested by fluorescence microscopy. Rectangular samples of potato parenchyma were incubated for $20 \mathrm{~h}$ at $4^{\circ} \mathrm{C}$ in a $25 \mu \mathrm{M}$ solution of propidium iodide (Sigma, $\lambda_{\mathrm{ex}}=536 \mathrm{~nm} ; \lambda_{\mathrm{em}}=617 \mathrm{~nm}$ ) in $10 \mathrm{mM}$ PBS buffer, $\mathrm{pH}$ 7.5. After the incubation time, samples were PEF-treated either with a single 1-ms pulse with strength of $200,300,400 \mathrm{~V} / \mathrm{cm}$ or with three $1-\mathrm{ms}$ pulses of $500 \mathrm{~V} / \mathrm{cm}$ (positive control for electroporation, based on preliminary tests showing leakage of cell contents after treatment). Untreated samples were used as negative controls. After treatment, a 1-mm-thick cross section was cut from the rectangle and immediately placed in $5 \mathrm{ml}$ PBS buffer for 3 min under slight agitation to wash away the excess of dye and starch from its surface. Microscopic observations of the cross section were made with a Nikon inverted fluorescence microscope (Nikon Co., Kawasaki, Japan) at a magnification of $10 \times$. Images were captured with an Olympus DP70 camera controlled by the DP CONTROLLER software (Olympus Co., Tokyo, Japan). Five slices from four different tubers were examined at each experimental condition.
Metabolic profile evaluation of the effect

of electrical treatments

\section{Sample preparation}

Ten rectangular samples were obtained from each of seven tubers and used for electrical treatments. From each set of ten samples, two were immediately submerged in liquid nitrogen (Time 0). Each of the other eight remaining samples were placed between two parallel, flat stainless steel electrodes, and treated at varying voltages. Thus, from the eight samples, two samples from the same tuber were not PEF-treated ("Wounded"), two samples were treated with a single 1-ms pulse of $200 \mathrm{~V} / \mathrm{cm}$, other two samples with a single $1 \mathrm{~ms}$ of $300 \mathrm{~V} / \mathrm{cm}$ and the other two with a single 1 -ms pulse of $400 \mathrm{~V} / \mathrm{cm}$.

Immediately after pulse delivery, PEF-treated samples and controls were taken out from the electrodes and placed in a $240-\mathrm{ml}$ closed plastic container with wet tissue in the bottom at $20^{\circ} \mathrm{C}$. Samples were taken out from the container 1 min after the delivery of the pulse, a piece was sliced from them with a sharp razor blade and immediately immersed in liquid nitrogen. The rest of the samples were taken back to the plastic container. One more piece of the samples was sliced $6 \mathrm{~h}$ after the delivery of the pulse and placed in liquid nitrogen. The rest of the samples was taken back to the plastic container and placed under liquid nitrogen $24 \mathrm{~h}$ after the delivery of the pulse.

Frozen pieces of potato tissue were ground to a fine powder using liquid nitrogen and a mortar and pestle. $10 \pm 1 \mathrm{mg}$ (fresh weight) of each sample was quickly weighed in a 1.5-ml "safety cap" Eppendorf tube. Tubes were immediately placed under liquid nitrogen and stored under $-80^{\circ} \mathrm{C}$ until analysis.

\section{Extraction}

For the extraction of metabolites, the sample powder in the Eppendorf tubes was mixed with a solution containing 20\% (v/v) $\mathrm{CHCl}_{3}, 20 \%$ (v/v) water, 60\% (v/v) methanol and 11 isotope-labelled internal standards $\left(\left[{ }^{13} \mathrm{C}_{5}\right]\right.$ proline, succinic acid-D4, salicylic acid-D6, $\left[{ }^{13} \mathrm{C}_{4}\right] \alpha$-ketoglutarate, $\left[{ }^{13} \mathrm{C}_{5}\right.$, $\left.{ }^{15} \mathrm{~N}\right]$ glutamic acid, putrescine-D4, myristic $\operatorname{acid}\left[{ }^{13} \mathrm{C}_{3}\right]$, $\left[{ }^{13} \mathrm{C}_{6}\right]$ glucose, $\left[{ }^{13} \mathrm{C}_{4}\right]$ hexadecanoic acid, $\left[{ }^{13} \mathrm{C}_{12}\right]$ sucrose and cholesterol-D7) (Gullberg et al. 2004). The ratio weight of sample:volume of solution was 1:73 (mg: $\mu \mathrm{l})$. The mixture was homogenized in a mixer mill (Retsch MM 40, Retsch Gmbh, Haan, Germany) for 3 min at maximum frequency $(30 \mathrm{~Hz})$, before centrifugation at $14,000 \mathrm{rpm}$ for $10 \mathrm{~min}$. The supernatant was carefully transferred to another container to be further used for GC/TOF-MS and UPLC/TOFMS analysis. 


\section{Derivatization and GC/TOF-MS analysis}

Two hundred microliter of the extracts was evaporated to dryness in a MiVac Quattro SpeedVac Concentrator (Genevac, Ipswich, UK). For methoximation, $30 \mu \mathrm{l}$ of methoxyamine $(15 \mu \mathrm{g} / \mu \mathrm{l}$ in pyridine) was added to the sample. After 16-h derivatization at room temperature, the sample was trimethylsilylated for $1 \mathrm{~h}$ using $30 \mu \mathrm{l}$ of MSTFA at $25^{\circ} \mathrm{C}$. $30 \mu \mathrm{l}$ of heptane (where $15 \mathrm{ng} / \mu \mathrm{l}$ of methyl stearate was added) was added following silylation. The derivatized samples were taken to analysis in the GC/TOF-MS.

Using a CTC Combi Pal system as an autosampler (CTC Analytics AG, Zwingen, Switzerland), $1 \mu 1$ of the derivatized sample was injected into an Agilent 6890 gas chromatograph equipped with a $10 \mathrm{~m} \times 0.18 \mathrm{~mm}$ i.d. fused capillary column with a chemically bonded $0.18 \mu \mathrm{m}$ DB 5-MS stationary phase (J\&W Scientific, Folsom, CA, USA). The injector temperature was $270^{\circ} \mathrm{C}$, the purge flow rate was $20 \mathrm{ml} / \mathrm{min}$ and the purge was turned on after $60 \mathrm{~s}$. The helium carrier gas flow rate through the column was $1 \mathrm{ml} / \mathrm{min}$, the column temperature was held at $70^{\circ} \mathrm{C}$ for $2 \mathrm{~min}$, then increased by $40^{\circ} \mathrm{C} / \mathrm{min}$ to $320^{\circ} \mathrm{C}$ and held there for $1 \mathrm{~min}$. The column effluent was introduced in the ion source of a Pegasus III time-offlight mass spectrometer, GC/TOF-MS (Leco Corp., St Joseph, MI, USA). The transfer line and the ion source temperatures were 250 and $200^{\circ} \mathrm{C}$, respectively. Ions were generated by a $70-\mathrm{eV}$ electron beam at an ionization current of $2.0 \mathrm{~mA}$ and $30 \mathrm{spectra} / \mathrm{s}$ were recorded in the mass range $50-800 \mathrm{~m} / \mathrm{z}$. The acceleration voltage was turned on after a solvent delay of $175 \mathrm{~s}$. The detector voltage was $1,500-2,000 \mathrm{~V}$.

\section{UPLC/TOF-MS analysis}

Two hundred microliter of the extracts was evaporated to dryness in the MiVac Quattro SpeedVac Concentrator. $10 \mu \mathrm{l}$ of methanol and $90 \mu \mathrm{l}$ of water containing $5 \mathrm{ng} / \mu \mathrm{l}$ of nalidixic acid were added to the sample. Chromatography was performed on a Waters Aquity UPLC system (Waters Corp, Milford, MA, USA). 8- $\mu$ l aliquot of sample was injected onto a $2.1 \times 100 \mathrm{~mm}, 1.7 \mu \mathrm{m}$ UPLC column (C18 UPLC column) held at $40^{\circ} \mathrm{C}$. The gradient elution buffers were $\mathrm{A}\left(\mathrm{H}_{2} \mathrm{O}, 0.1 \%\right.$ formic acid) and B (acetonitrile, $0.1 \%$ formic acid), and the flow rate was $500 \mu \mathrm{l} / \mathrm{min}$. The column was eluted with a linear gradient consisting of $1-20 \%$ B over 0-3 min, $20-40 \%$ of B over $3-5 \min , 40-95 \%$ B over 5-8 $\mathrm{min}$ and $95-100 \%$ B over $8-12.5 \mathrm{~min}$. The composition was held at $100 \% \mathrm{~B}$ for $3.5 \mathrm{~min}$ and returned to $1 \% \mathrm{~B}$ at $19 \mathrm{~min}$. The composition was kept at $1 \% \mathrm{~B}$ for a further $0.5 \mathrm{~min}$ before the next injection. The UPLC was coupled to a Micromass LCT premier time-of-flight (Tof) mass spectrometer equipped with an electrospray source operat- ing in negative ion mode with lockspray interface for accurate mass measurements. The source temperature was $120^{\circ} \mathrm{C}$ with a cone gas flow of $10 \mathrm{l} / \mathrm{h}$, a desolvation temperature of $320^{\circ} \mathrm{C}$ and a nebulization gas flow of $600 \mathrm{l} / \mathrm{h}$. The capillary voltage was set at $2.5 \mathrm{kV}$ for negative ion mode, with a cone voltage of $0 \mathrm{~V}$, a data acquisition rate of $0.1 \mathrm{~s}$, an interscan delay of $0.1 \mathrm{~s}$, with dynamic range enhancement (DRE) mode activated. Leucine enkephalin was employed as the lock mass compound, infused straight into the MS at a concentration of $400 \mathrm{pg} / \mu \mathrm{l}$ (in $50: 50$ $\mathrm{ACN}$ :water) at a flow rate of $40 \mu \mathrm{l} / \mathrm{min}$. The normal lock mass in the DRE mode was the negative ion second 13C peak of leucine enkephalin at 555.2645, and the extended lock mass peak was the negative ion peak observed at 554.2615 .

All mass spectral data were acquired in the centroid mode, $50-1,000 \mathrm{~m} / \mathrm{z}$, with a data threshold value set to 3 .

\section{Processing of metabolites data}

Non-processed MS data from GC/TOF-MS analysis were exported in NetCDF format to MATLAB 7.0 (Mathworks, Natick, MA, USA), where all data-pretreatment procedures, such as smoothing, alignment, time-window setting, and hierarchical multivariate curve resolution (H-MCR), were carried out (Jonsson et al. 2004, 2006). The resolved MS spectra were matched against reference mass spectra using the NIST (National Institute of Standards and Technology, Gaithersburg, MD, USA) mass spectral search program 2.0. Peaks were identified or annotated based on retention indices (RIs) and the reference mass spectra comparison to the following databases: commercial database from NIST v. 2.0, the Umeå Plant Science Centre (Umeå, Sweden) in-house metabolomics database and the Max Plank Institute for Molecular Plant Physiology (Postdam, Germany) in-house metabolomics database.

MS data from the UPLC/TOF-MS were processed using the MASSLYNX software 4.1 (Waters Corp, Milford, MS, USA). Within this software, QUANLYNX was used for relative quantification of metabolites, were MS spectra were matched with the spectra of previously analyzed standards of $\alpha$-solanine, $\alpha$-chaconine, chlorogenic acid, sinapic acid, ferulic acid, cinnamic acid, coumaric acid and caffeic acid. The concentration of each of these compounds in the treated samples was compared with that of the Time 0 samples for making a relative quantification. Salicylic acid, previously added to all samples, was used as internal standard for instrumental drift correction. All standards, with $>98 \%$ purity, were provided by Sigma (Sigma-Aldrich, Sweden). In the $\alpha$-solanine and $\alpha$-chaconine standards, the adduct $[\mathrm{M}+$ $\mathrm{HCOO}^{-}$was the most dominant one and, therefore, used for the relative quantification. 


\section{Statistical analysis for metabolic profiling}

After peak annotation, the obtained data matrix after GC/ TOF-MS analysis was normalized using the concentrations of the 11 internal standards. After normalization, the matrix was used for multivariate analysis. The orthogonal projections to latent structures (OPLS) method was performed as a supervised multivariate analysis with SIMCA-P + 11.5 software (Umetrics AB, Umeå, Sweden). The OPLS method divides the systematic variation of the $X$-block (predictor variables) into two model parts, one part which models the co-variation between $X$ and $Y$ (response variables) and another part which expresses the $X$ variation that is not related (orthogonal) to $Y$. This leads to a better class resolution in a discriminant problem (Bylesjö et al. 2006).

In order to narrow down the variables (metabolites) most influential to the separation of the groups in the OPLS model, weight plots $\left(\mathrm{w}^{*} \mathrm{c}[2] \mathrm{O}\right.$ vs. $\left.\mathrm{w}^{*} \mathrm{c}[1] \mathrm{P}\right)$ showing relationships between all factors and responses, as well as variable importance plots were used. On the selected variables, one-way ANOVA was performed using MINITAB 12 software (Minitab Inc., State College, PA, USA) to define those showing statistically significant differences between the treatments.

Statistically significant differences between the analyzed compounds in the UPLC/TOF-MS were tested using the MINITAB 12 software.

\section{Results}

Electroporation and tissue survival

The electroporation experienced by the samples at the applied PEF conditions is demonstrated by the penetration of propidium iodide in the cells and the staining of their nucleus (Fig. 1), which can be clearly seen in the pictures as bright circles inside the cells. An increasing amount of nuclei can be seen in the samples as the electric field treatment intensity increases. This observation could be attributed to the heterogeneity of the cells in the potato parenchyma. It has been shown that electropermeabilization in plant tissues depends on the cell size, shape and orientation (Weaver 1993); heterogeneity of cells in the sample would be a crucial factor influencing the required energy for electroporation (Chalermchat 2005).

The observed electroporation was also reflected by the drop of the resistance of the tissue samples during the pulsing period (Fig. 2), where the final electrical resistance of the potato sample during the delivery of the pulse is plotted against the applied nominal electric field strength. As the applied voltage and the reference resistance are constant and the sample resistance changes during the pulse, the actual field strength experienced by the tissue varies. The initial field strength was within $10 \%$ of the nominal field strength for the samples. In a separate experiment, we found that the contact resistance was negligible. Upon
Fig. 1 Typical experimental results from microscopic observations of potato tissue treated with electric fields and stained with propidium iodide, as indicated in "Materials and methods". The red channel of the original images is shown. a Untreated sample (negative control). b Samples treated with a single $1-\mathrm{ms}$ pulse of $200 \mathrm{~V} / \mathrm{cm}$. c Samples treated with a single 1 -ms pulse of $300 \mathrm{~V} / \mathrm{cm}$. d Samples treated with three 1 -ms pulse of $500 \mathrm{~V} / \mathrm{cm}$ (positive control)
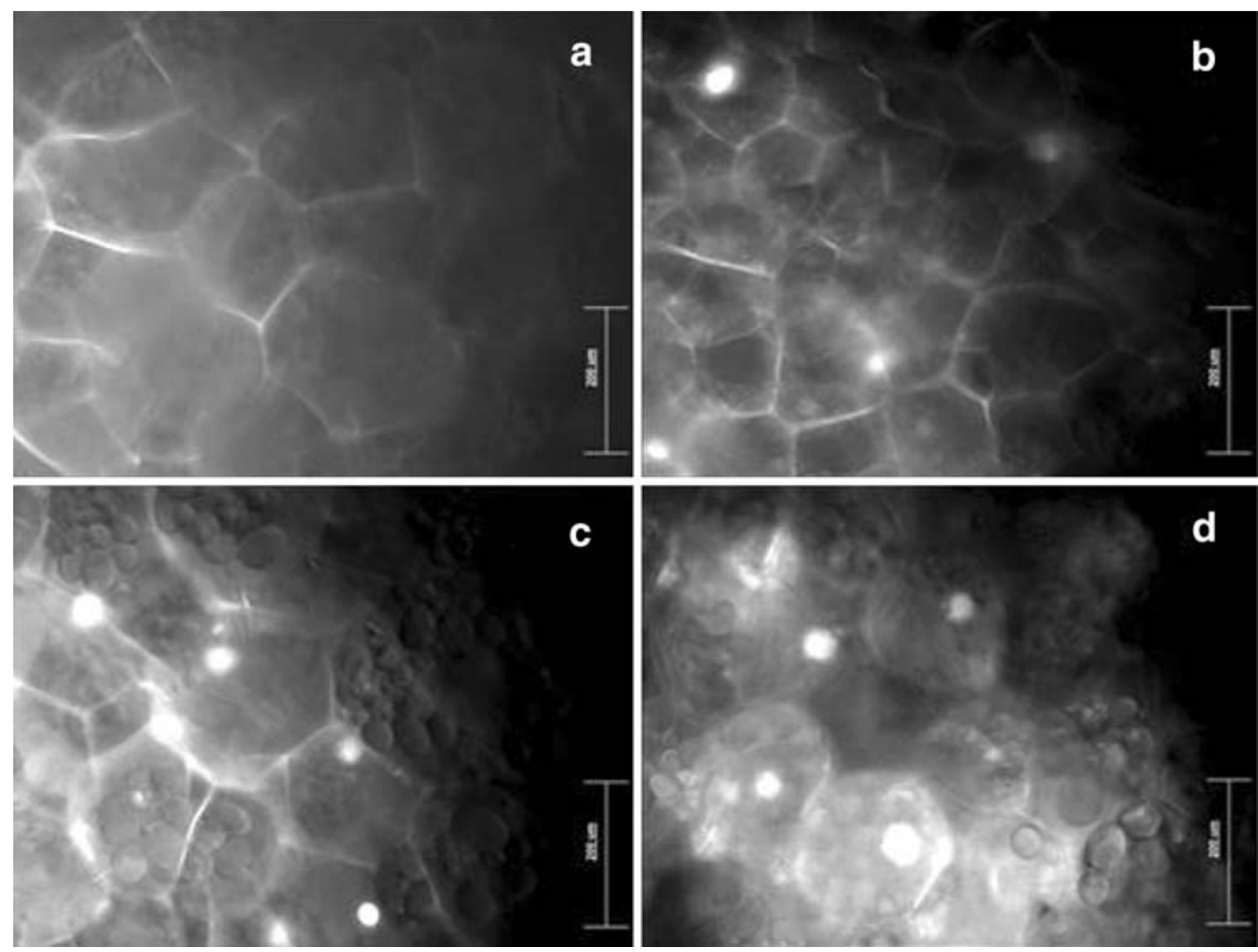


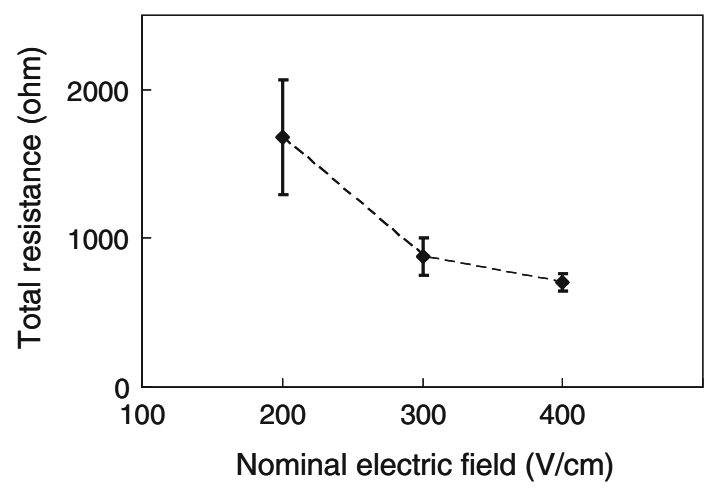

Fig. 2 Total resistance of potato samples during the application of a single 1-ms unipolar, rectangular pulse at different field strengths. Each given value is the average of four replicates. Error bars are the standard deviation of the mean

pulsation, tissue resistance decreased markedly from 200 to $300 \mathrm{~V} / \mathrm{cm}$, followed by a slight decrease after $300 \mathrm{~V} / \mathrm{cm}$.

At the field intensities of 200 and $300 \mathrm{~V} / \mathrm{cm}$, the measurement of the impedance of the samples 6 and $24 \mathrm{~h}$ after pulse delivery revealed the impedance to be essentially identical to that of the untreated sample, indicating that 1-ms pulse treatment at those field strengths did not induce permanent permeabilization of the tissue and the leakage of its cell contents. The impedance of samples treated at $400 \mathrm{~V} / \mathrm{cm}$ decreased $6 \mathrm{~h}$ after pulse delivery and was substantially lower $24 \mathrm{~h}$ after pulse delivery, presenting evidence of permanent permeabilization. Samples treated at $400 \mathrm{~V} / \mathrm{cm}$, showed visual evidence of microbial attack $24 \mathrm{~h}$ after pulse delivery.

Cluster analysis of metabolic profiles

After untargeted GC/TOF-MS analysis (for an example of a raw chromatogram, see Fig. 3), the $\mathrm{H}-\mathrm{MCR}$ process extracted 154 metabolite peaks and their mass spectra. Using the databases, 64 peaks were identified or annotated as known metabolites (Table 1). In addition, 33 peaks were annotated with mass spectral tags (MSTs) (Schauer et al. 2005). These peaks were consistently observed though not identified completely. Forty-three peaks were neither identified nor annotated with MSTs (unknowns).

OPLS was applied to all metabolic peaks for all treatments at each time point (Fig. 4a-c). Data obtained at $400 \mathrm{~V} / \mathrm{cm}$ were not included in the analysis at 6 and $24 \mathrm{~h}$ because cell death and microbial contamination were suspected. No cluster separation was noticed $1 \mathrm{~min}$ after the potato was either wounded or PEF-treated. Six hours after application of the treatments, two clusters were observed: samples obtained from the fresh tissue (Time 0) and treated samples, without any discrimination between the wounded and the PEF-treated tissue. Twenty-four hours after the application of the treatments, three clusters were clearly observed, the metabolites from fresh tissue, those of the wounded tissue and those of the PEF-treated tissue, without any discrimination between the intensities of the applied electric field.

\section{Specific responses to wounding and PEF stress}

The OPLS clustering was further analyzed as follows: (1) the fresh tissue (Time 0) differentiated from the tissue 6 and $24 \mathrm{~h}$ after wounding. (2) The tissue $24 \mathrm{~h}$ after wounding from the tissue $24 \mathrm{~h}$ after it was wounded and PEF-treated. Thus, metabolites contributing to the described clustering, differentiating metabolic responses between wounding specific effects and PEF-specific effects could be analyzed. As detailed in "Materials and methods", weight and variable importance plots together with ANOVA analysis were used to select the discriminative metabolites. The list of the metabolites shown to

Fig. 3 Typical GC chromatogram of potato extracts

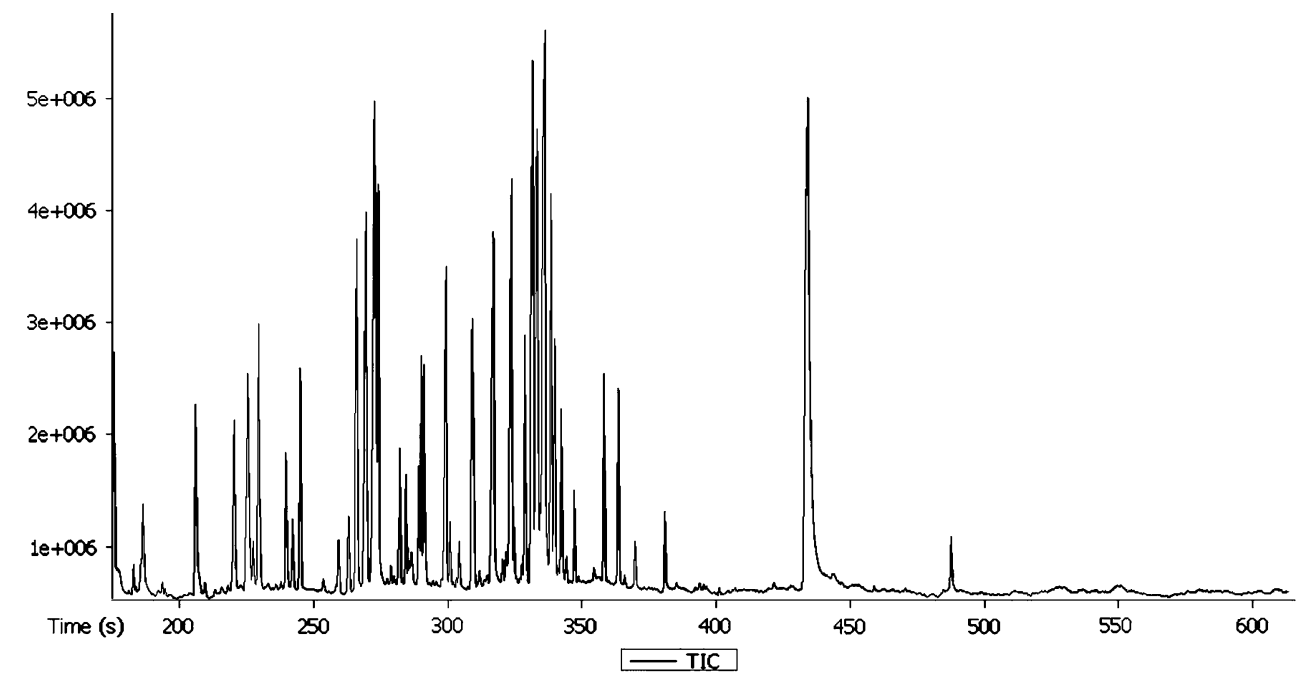


Table 1 Metabolites identified in profiles of extracts after untargeted GC/TOF-MS analysis

\begin{tabular}{|c|c|c|c|}
\hline Amino acids & Organic acids & Sugars & Other \\
\hline Alanine & 2-Aminobutyric (TMS) $)_{2}$ & Fructose meox $1(\mathrm{TMS})_{5}$ & $t$-Caffeic acid (TMS) $)_{3}$ \\
\hline$\beta$-Alanine $(\mathrm{TMS})_{3}$ & 4-Aminobutyric & Fructose meox $2(\mathrm{TMS})_{5}$ & 2,5-Diaminovalerogalactam (TMS $)_{2}$ \\
\hline Allothreonine $(\mathrm{TMS})_{3}$ & Citric $(\mathrm{TMS})_{4}$ & Galactinol $(\mathrm{TMS})_{9}$ & Diethyleneglycol (TMS) $)_{2}$-like compound ${ }^{\mathrm{a}}$ \\
\hline L-Arginine (TMS) & Dehydroascorbic acid dimer (TMS) & Glucose meox $1(\mathrm{TMS})_{5}$ & Digalactosylglycerol-like compound ${ }^{\mathrm{a}}$ \\
\hline Aspartic acid (TMS) & Fumaric (TMS) $)_{2}$ & Glucose meox $2(\mathrm{TMS})_{5}$ & Ethanolamine $(\mathrm{TMS})_{3}$ \\
\hline L-Aspartic acid $(\text { TMS })_{2}$ & Fumaric & D-Maltose meox $1(\mathrm{TMS})_{8}$ & Glucose-6-phosphate meox 1 (TMS) 6 \\
\hline L-Asparagine $(\mathrm{TMS})_{3}$ & Glyceric $(\mathrm{TMS})_{3}$ & Melibiose meox $1(\mathrm{TMS})_{8}$ & Inositol (TMS) 6 \\
\hline L-Asparagine (TMS) ${ }_{4}$ & Glyceric acid $(\mathrm{TMS})_{3}$ & Raffinose $(\text { TMS })_{11}$ & myo-Inositol-1-phosphate (TMS) ${ }_{7}$ \\
\hline Glutamic acid & Glutaric & Sucrose $(\mathrm{TMS})_{8}$ & $\beta$-D-methylglucopyranoside \\
\hline Glutamine (TMS) & Hexadecanoic acid & & Phosphoric $(\mathrm{TMS})_{3}$ \\
\hline Glutamine $(\mathrm{TMS})_{4}$ & Itaconic $(\mathrm{TMS})_{2}$ & & Putrescine-like compound ${ }^{\mathrm{a}}$ \\
\hline L-Glutamine $(\mathrm{TMS})_{3}$ & $\alpha$-Linoleic acid (TMS) & & Sterol like compounds $(2)^{\mathrm{a}}$ \\
\hline Glycine $(\mathrm{TMS})_{3}$ & Malic $(\mathrm{TMS})_{3}$ & & Uracil-like compound (TMS)a \\
\hline L-Histidine $(\mathrm{TMS})_{3}$ & Malonic & & \\
\hline Leucine (TMS) & Oxalic-like compound ${ }^{\mathrm{a}}$ & & \\
\hline Lysine $(\mathrm{TMS})_{4}$ & D-Quinic (TMS) $)_{5}$ & & \\
\hline Ornithine $(\mathrm{TMS})_{3}$ & Stearic acid (TMS) & & \\
\hline Nicotianamine $(\mathrm{TMS})_{4}$ & Threonic (TMS) ${ }_{4}$ & & \\
\hline L-Phenylalanine (TMS) ${ }_{2}$ & & & \\
\hline Pyroglutamic acid (TMS) & & & \\
\hline Serine & & & \\
\hline L-Tyrosine $(\mathrm{TMS})_{3}$ & & & \\
\hline Tryptophan (TMS) & & & \\
\hline Valine (TMS) & & & \\
\hline
\end{tabular}

a Only the metabolic class of these components was identified

be significantly affected $6 \mathrm{~h}$ after wounding is reported in Table 2. A decrease in the glutamic acid is accompanied by either the increase or decrease of seven unknown compounds. As pointed out above, no PEF-specific effects could be identified $6 \mathrm{~h}$ after the treatment.

Metabolites shown to be significantly affected $24 \mathrm{~h}$ after wounding are highlighted with a circle in a simplified metabolic pathway map (Fig. 5). Only known compounds are reported in Fig. 5. Results from the UPLC/ TOF-MS are also included in the figure. Additionally, the following NSTs and unknown compounds were specifically affected by wounding: M000000_A228001101 (RI: 2,263.2 s), UPSC_20182 (RI: 2,528.5 s), unknown (RI: 2,839.1 s), unknown (RI: 3,210.2 s). Metabolites are annotated red for increased concentration and blue for decreased concentration.

Differences of metabolites obtained $24 \mathrm{~h}$ after the tissue was wounded and PEF-treated are highlighted in Fig. 5 as PEF-specific effects. Additionally, the decrease of a compound identified with the NST M000000_A12002101 (RI: 1,244.4) was also identified as specific for the PEF response. When the wounded tissue has been subjected to an electric field, its overall metabolic response is apparently the same as the wounding response regarding the changes in the amino acid pool and the tendency to increase the levels of sterol and galactosyl glycerol-like compounds. Interestingly, the metabolic response after PEF stress differentiates from wounding in the hexose pool. There is an accumulation of sucrose and fructose as well as an accumulation of threonic acid, a degradation product of ascorbic acid, which will eventually contribute to the hexose pool (Loewus 1999).

Another interesting deviation of the wounding-specific response when PEF is applied is the high level of quinate and low level of chlorogenic acid. Chlorogenic acid constitutes up to $90 \%$ of the total phenolic content of potato tubers and is an important defence-related compound, protecting potatoes from attack by phytopathogens and insects (Friedman 1997), and it is accumulated in wound-healing potatoes as a part of their defence mechanism. Surprisingly, the concentration of chlorogenic acid of the PEF-treated tissue is similar to 

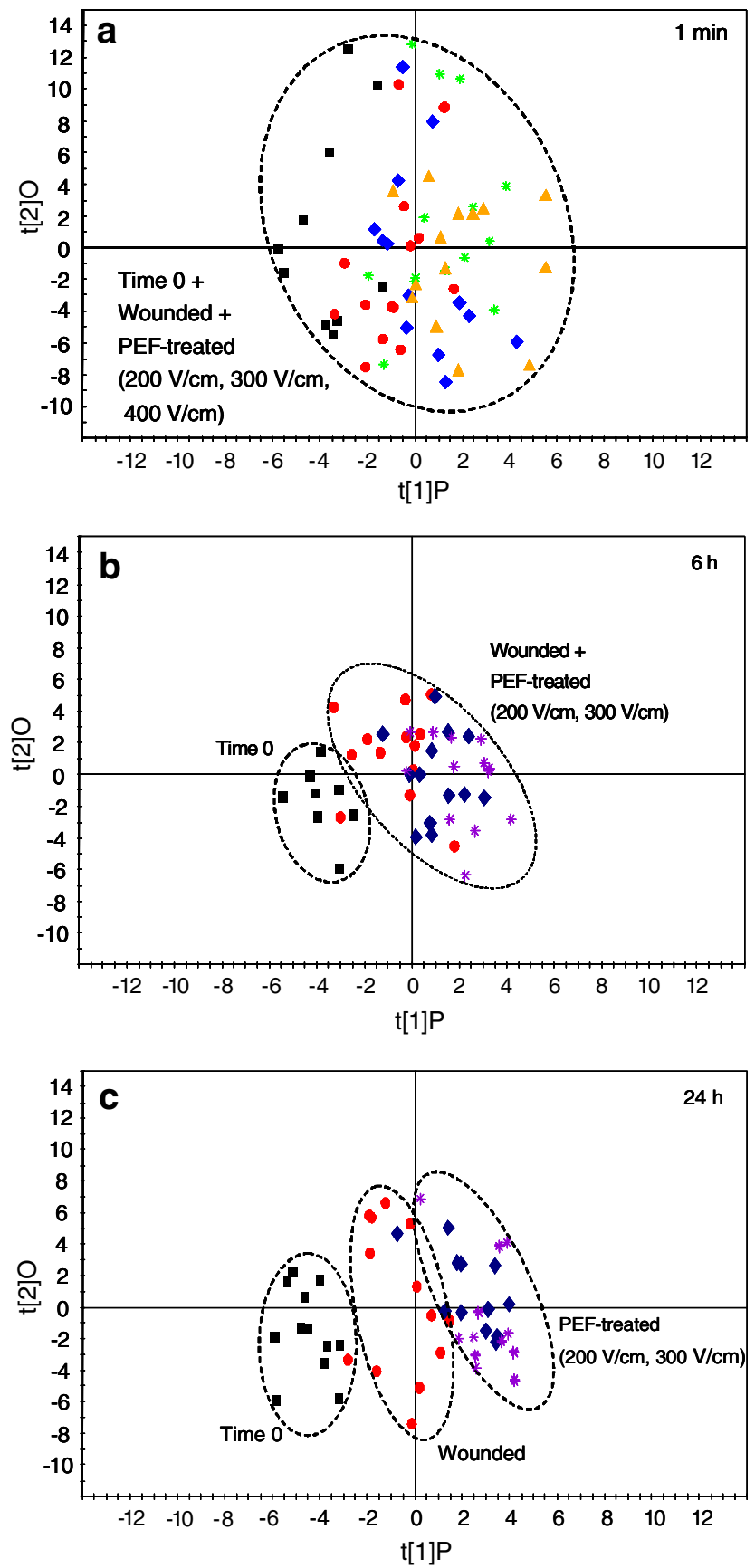

Fig. 4 Orthogonal projections to latent structures (OPLS) analysis of metabolites from samples of potato parenchyma subjected to different treatments. Samples were either (filled square) untreated (Time 0), (filled circle), wounded or (filled diamond, asterisk, grey triangle) wounded and PEF-treated at varying voltages, as described in "Materials and methods". Clustering analysis of samples is reported for $1 \mathrm{~min}(\mathbf{a}), 6 \mathrm{~h}(\mathbf{b})$ and $24 \mathrm{~h} \mathrm{(c)} \mathrm{after} \mathrm{treatments}$

that of the fresh potato (Time 0). Visual assessment of the potato samples did not reveal differences in the levels of enzymatic browning between the wounded and the PEF-treated tissue that could justify the differences in the levels of chlorogenic acid.
Table 2 Metabolites significantly affected $6 \mathrm{~h}$ after wounding

\begin{tabular}{ll}
\hline Wounding-specific response $6 \mathrm{~h}$ after treatment \\
\hline Metabolites & Wounding-specific response \\
\hline Glutamic acid & D \\
UPSC_10087 [1568.7] & I \\
UPSC_10122 [1695.8] & I \\
UPSC_20058 [1759.6] & I \\
UPSC_20178 [2407.2] & I \\
Unknown [1682.3] & I \\
Unknown [2314.8] & D \\
Unknown [3210.2] & D
\end{tabular}

The retention index of the components is reported in brackets

$D$ decrease of concentration, $I$ increase of concentration

\section{Discussion}

Metabolic profiles vary between wounded and PEF-treated samples

Our results demonstrate that $24 \mathrm{~h}$ after the application of PEF, potato metabolism shows PEF-specific responses characterized by the changes in the hexose pool that may involve starch and ascorbic acid degradation. In potatoes, accumulation of sucrose and other hexoses has been reported to be a common stress response when the stressor, such as cold temperatures and drought, targets the plasma membrane and may produce electrolyte leakage (Herppich et al. 2001; Blenkinsop et al. 2004). This sugar accumulation has been directly correlated with starch degradation (Blenkinsop et al. 2004). Increase in soluble sugars may play a role in osmoregulation and possibly also in the activation of respiratory metabolism (Espen et al. 1999). Osmoregulation might be very relevant for the case of PEF stress as cells in the tissue might experience a significant osmotic imbalance after pulsing but not after wounding, with different metabolic consequences.

In the case of wounding stress, it induces a cascade of short- and long-term metabolic events, which are well described in the literature. Short-term metabolic responses include an initial burst of ROS (oxidative burst) (Bolwell et al. 1995). In wounded potatoes, this burst reaches a maximum within 30-60 min. Another well-documented shortterm response is the cross-linking of hydroxyproline-rich glycoproteins at the cell wall which is taken place within 1 min after wounding (Bradley et al. 1992). In the long term, biosynthesis of suberin takes place at the cut surface (Bernards et al. 1999). Biosynthesis of suberin involves both primary and secondary metabolism and, therefore, a wide range of metabolites are likely to be involved in the 


\section{PEF-specific effects}

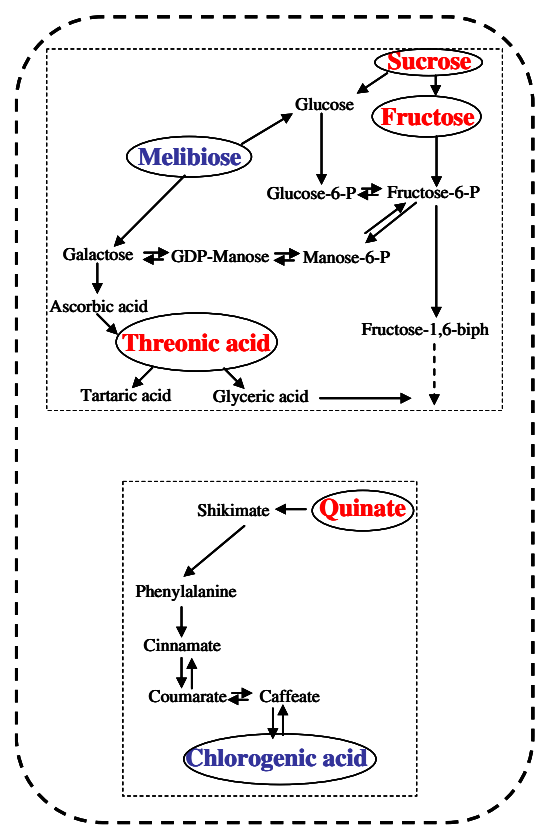

Wounding-specific effects

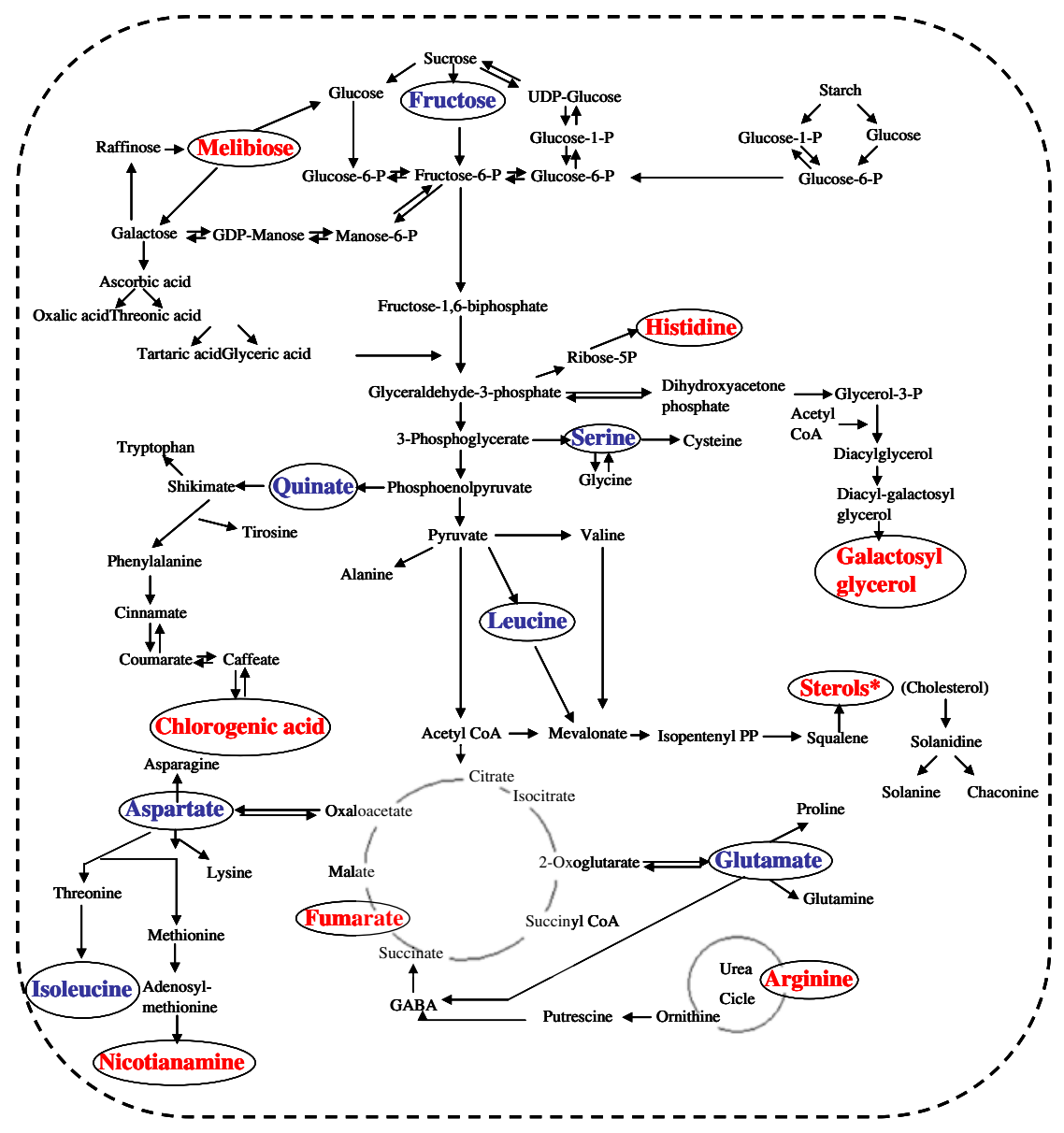

highlighted in the simplified metabolic maps with a circle. Metabolites are annotated red for increased concentration and blue for decreased concentration process (Yang and Bernards 2007). The initial deposition of suberin in potato requires approximately $18 \mathrm{~h}$ at $18^{\circ} \mathrm{C}$ (Lulai and Corsini 1998) and reaches a stage in which the suberized layer has sufficient structural integrity to be peeled off intact 3 days after wounding (Razem and Bernards 2002). In the wounded tissue, an increase of chlorogenic acid takes place, which is also a well-known response, improving the tissue protection against oxidative stress. Chlorogenic acid is known to increase up to $50 \%$ in wound-healing potatoes, $12 \mathrm{~h}$ after wounding (Matsuda et al. 2003). Cell membrane-related metabolites such a sterol-like compound (RI: 3,332.6 s) and a digalactosylglycerol-like compound (polar lipid, RI: 3,111.6 s) significantly increased their concentration upon wounding. The influence of different stressors such as wounding and light on the increased expression of sterol-biosynthetic genes has been reported in potatoes (Piironen et al. 2000).

Twenty-four $\mathrm{h}$ after wounding, most of the metabolites showing significant changes were amino acids, including the non-proteinogenic nicotianamine, which is known to play an important role in scavenging of $\mathrm{Fe}^{\mathrm{III}}$ and $\mathrm{Fe}^{\mathrm{II}}$, being part of the protecting mechanisms of cells from oxidative damage (von Wirén et al. 1999). Mature potato tubers respond to wounding by synthesizing several polypeptides (Vayda and Schaeffer 1988) that appear to have structural roles in the cell wall (for review, see Showalter and Varner 1987). This is a common response to wounding and, therefore, it is not surprising that Fig. 5 shows that the amino acid pool has been affected. Changes in the amino acid pool upon wounding (Yang and Bernards 2007), cold stress (Kaplan et al. 2007), heat stress (Kaplan et al. 2004) and drought (Rizhsky et al. 2004) have been previously reported. The concentration of amino acids derived from glycolysis intermediates as well as from the citric acid cycle was affected.

The wounding stress is triggered by the cells immediately below the cut surface. In contrast, it is very likely that PEF induces stress responses through targeting all exposed 
cells. In the case of our experiments, we assume that all cells of the tissue were uniformly exposed to the electric field. To our knowledge, only short-term responses (time scale of minutes) to PEF stress have been described, including oxidative burst and cell wall structural changes (Gómez Galindo et al. 2008a, b), responses that are apparently analogous to the short-term wounding response. In this investigation, OPLS analysis strongly suggests that the PEF treatment affects significantly the tissue metabolome only in the long term (time scale of hours).

\section{New insights into the PEF stress response}

The application of metabolic profiling and clustering analysis has provided new insights into the response to a stressor such as PEF that is unique and does not exist in nature, providing enlightening results on how potato tissue responds to a physical stimulus which is an artificial stress.

With the application of PEF, opening of pores in the plasma membrane will result in the efflux and influx of polar molecules. After the pulse application, resealing process takes place in a time scale of seconds or minutes. After resealing, the cell membrane recovers its properties in a long-term physiological process that may take from several hours to days (Teissié et al. 2005). This process might involve ATPase activity, which uses the chemical energy of ATP, helping the cells to take up the leaked ions against the concentration gradient (Arora and Palta 1991). This hypothesis of the high metabolic energy requirements during the recovery process is supported by our results suggesting that the wounded tissue subjected to PEF is actively mobilizing its carbon energy sources that might involve starch and ascorbic acid degradation, contributing to the hexose pool.

The time scale of hours where the reported PEF-specific effects took place agrees with the time scale needed for the recovery process. It is still surprising that our results did not present any evidence of PEF-specific changes in the metabolome immediately after pulse, where some enzymes might come in contact with their substrates as a consequence of electroporation-driven migration of cell contents. Six hours after PEF application, the changes in the hexose pool are still not significant.

Our results could not confirm the results reported by other authors (Guderjan et al. 2005, 2007; Balasa 2007) showing an increase of antioxidants or polyphenols, which could be attributed to a PEF-induced stress response. Our results do not show evidence of chlorogenic acid accumulation on PEF-treated potato. Potato metabolism is dealing with two stressors, wounding and electroporation and its stress response might be different from that of tissues exposed only to one stressor. Further investigations directed towards the genetic control of the described meta- bolic changes would provide a deeper understanding of the mechanisms behind the response to these multiple stimuli.

Acknowledgments The authors are grateful to Prof. Susanne Widell from the Department of Cell and Organism Biology, Lund University, Sweden, for the use of microscopic facilities. This study was supported by grants from the Portuguese Foundation of Science (FCT, Portugal) and The Royal Physiographic Society in Lund, Sweden.

\section{References}

Aronsson K, Lindgren M, Johansson BR, Rönner U (2001) Inactivation of microorganisms using pulsed electric fields: the influence of process parameters on Escherichia coli, Listeria innocua, Leuconostoc mesenteroides and Saccharomyces cerevisiae. Innov Food Sci Emerg Tech 2:41-54

Arora R, Palta JP (1991) A loss in the plasma membrane ATPase activity and its recovery coincides with incipient freeze-thaw injury and post-thaw recovery in onion bulb scale tissue. Plant Physiol 95:846-852

Baker CJ, Orlandi EW (1995) Active oxygen in plant pathogenesis. Annu Rev Phytopathol 33:99-321

Balasa A (2007) Impact of pulses electric field treatment on stability and production of health related components in plant tissue. Available via DIALOG. http://www2.tu-berlin.de/ foodtech/ pdf/balasa.pdf

Beckmann M, Enot DP, Overy DP, Draper J (2007) Representation, comparison, and interpretation of metabolome fingerprint for total composition analysis and quality trait investigation in potato cultivars. J Agric Food Chem 55:3444-3451

Bernards MA, Fleming WD, Llewellyn DB, Priefer R, Yang X, Sabatino A, Plourde GL (1999) Biochemical characterization of the suberization-associated anionic peroxidase of potato. Plant Physiol 121:135-145

Blenkinsop RW, Yada RY, Marangoni AG (2004) Metabolic control of low-temperature sweetening in potato tubers during postharvest storage. Hortic Rev 30:317-354

Bolwell GP, Butt VS, Davies DR, Zimmerlin A (1995) The origin of the oxidative burst in plants. Free Radical Res 6:517-532

Bradley DJ, Kjelbom P, Lamb CJ (1992) Elicitor-and wound-induced oxidative cross-linking of a proline-rich plant cell wall protein: a novel, rapid defense response. Cell 70:21-30

Bylesjö M, Rantalainen M, Cloarec O, Nicholson JK, Holmes E, Trygg J (2006) OPLS discriminant analysis: combining the strengths of PLS-DA and SIMCA classification. J Chemom 20:341-351

Chalermchat Y (2005) Effects of pulsed electric fields on plant tissue. Dissertation, Lund University

Dunn WB, Bailey NJC, Johnson HE (2005) Measuring the metabolome: current analytical technologies. Analyst 130:606-625

Espen L, Morgutti S, Abruzzese A, Negrini N, Rivetta A, Quattrini MM, Cocucci M, Cocucci SM (1999) Changes in the potato (Solanum tuberosum L.) tuber at the onset of dormancy and during storage at $23^{\circ} \mathrm{C}$ and $3{ }^{\circ} \mathrm{C}$. I. Biochemical and physiological parameters. Potato Res 42:189-201

Friedman M (1997) Chemistry, biochemistry, and dietary role of potato polyphenols. A review. J Agric Food Chem 45:1523-1540

Gabriel B, Teissié J (1994) Generation of reactive oxygen species induced by electropermeabilization of Chinese hamster ovary cells and their consequence on cell viability. Eur J Bioch 223:25-33

Gómez Galindo F, Sjöholm I, Rasmusson AG, Widell S, Kaack K (2007) Plant stress physiology: opportunities and challenges for the food industry. Crit Rev Food Sci Nut 47:729-763 
Gómez Galindo F, Vernier T, Dejmek P, Vicente A, Gundersen M (2008a) Pulsed electric field reduces the permeability of potato cell wall. Bioelectromagnetics 29:296-301

Gómez Galindo F, Wadsö L, Vicente A, Dejmek P (2008b) Exploring metabolic responses of potato tissue induced by electric pulses. Food Biophysics 3:352-360

Gray GR, Heath D (2005) A global reorganization of the metabolome in Arabidopsis during cold acclimation is revealed by metabolic fingerprinting. Physiol Plant 124:236-248

Guderjan M, Topfl S, Angersbach A, Knorr D (2005) Impact of pulsed electric field treatment on the recovery and quality of plant oils. J Food Eng 67:281-287

Guderjan M, Elez-Martínez P, Knorr D (2007) Application of pulsed electric fields at oil yield and content of functional food ingredients at the production of rapeseed oil. Innov Food Sci Emreg Tech $8: 55-62$

Gullberg J, Jonsson P, Nordstöm A, Sjöström M, Moritz T (2004) Design of experiments: an efficient strategy to identify factors influencing extraction and derivatization of Arabidopsis thaliana samples in metabolomic studies with gas chromatography/mass spectrometry. Anal Biochem 331:283-295

Herppich WB, Linke M, Landahl S, Gzik A (2001) Pre-harvest and postharvest responses of radish to reduced water supply during growth. Acta Hort 553:89-90

Hu F, Furihata K, Kato Y, Tanokura M (2007) Nondestructive quantification of organic compounds in whole milk without pretreatment by two-dimensional NMR spectroscopy. J Agric Food Chem 55:4307-4311

Huhman DV, Sumner LW (2002) Metabolic profiling of saponines in Medicago sativa and Medicago truncatula using HPLC coupled to an electrospray ion-trap mass spectrometer. Phytochemistry 59:347-360

Jeong ML, Jiang H, Chen HS, Tsai CJ, Harding SA (2004) Metabolic profiling of the sink-to-source transition in developing leaves of quaking aspen. Plant Physiol 136:3364-3375

Jonsson P, Gullberg J, Nordström A, Kusano M, Kowalczyk M, Sjöström M, Moritz T (2004) A strategy for identifying differences in large series of metabolic samples analysed by GC/MS. Anal Chem 76:1738-1745

Jonsson P, Johansson ES, Wuolikainen A, Lindberg J, SchuppeKoistinen I, Kusano M, Sjöström M, Trygg J, Moritz T, Antti H (2006) Predicting metabolite profiling applying hierarchical multivariate curve resolution to GC-MS data-a potential tool for multi-parametric diagnosis. J Proteome Res 5:1407-1414

Kaplan F, Kopka J, Haskell DW, Zhao W, Schiller KC, Gatzke N, Sung DY, Guy CL (2004) Exploring the temperature-stress metabolome of Arabidopsis. Plant Physiol 136:4159-4168

Kaplan F, Kopka J, Sung DY, Zhao W, Popp M, Porat R, Guy CL (2007) Transcript and metabolite profiling during cold acclimation of Arabidopsis reveals an intricate relationship of cold-regulated gene expression with modifications in metabolite content. Plant J 50:967-981

Loewus FA (1999) Biosynthesis and metabolism of ascorbic acid in plants and of analogs of ascorbic acid in fungi. Phytochemistry 52:193-210

Lulai EC, Corsini DL (1998) Differential deposition of suberin phenolic and aliphatic domains and their roles in resistance to infection during potato tuber (Solanum tuberosum L.) wound-healing. Physiol Mol Plant Path 53:209-222

Matsuda F, Morino K, Miyashita M, Miyagawa H (2003) Metabolic flux analysis of the phenylpropanoid pathway in wound-healing potato tuber tissue using stable isotope-label tracer and LC-MS spectroscopy. Plant Cell Physiol 44:510-517
Mattivi F, Guzzon R, Vrhovsek U, Stefanini M, Velasco R (2006) Metabolite profiling of grape: flavonoids and anthocyanins. J Agric Food Chem 54:7692-7702

Moco S, Bino RJ, Vorst O, Verhoeven HA, de Groot J, van Beek TA, Vervoort J, de Vos RCH (2006) A liquid chromatography-mass spectrometry-based metabolome database for tomato. Plant Physiol 141:1205-1218

Pereira GE, Gaudillere JP, Pieri P, Hilbert G, Maucourt M, Deberde C, Moing A, Rolin D (2006) Microclimate influence on mineral and metabolomic profiles of grape berries. J Agric Food Chem 54:6765-6775

Piironen V, Lindsay DG, Miettinen TA, Toivo J, Lampi AM (2000) Plant sterols, biosynthesis, biological function and their importance to human nutrition. J Sci Food Agric 80:939-966

Razem F, Bernards MA (2002) Hydrogen peroxide is required for ploy(phenolic) domain formation during wound-induced suberization. J Agric Food Chem 50:1009-1015

Rizhsky L, Liang H, Shuman J, Shulaev V, Davletova S, Mittler R (2004) When defense pathways collide. The response of Arabidopsis to a combination of drought and heat stress. Plant Physiol 134:1683-1696

Roessner U, Hegemann B, Lytovchenko A, Carrari F, Bruedigam C, Granot D, Fernie AR (2003) Metabolic profiling of transgenic tomato plants overexpressing hexokinase reveals that the influence of hexose phosphorylation diminishes during fruit development. Plant Physiol 133:84-99

Sabri N, Pelissier B, Teissié J (1996) Electropermeabilization of intact maize cells induces an oxidative stress. Eur J Bioch 238:737-743

Schauer N, Steinhauser D, Strelkov D, Scomburg D, Allison G, Moritz T, Lundgren K, Roessner-Tunali U, Forber MG, Willmitzer L, Fernie AR, Kopka J (2005) CG-MS libraries for the rapid identification of metabolites in complex biological samples. FEBS Lett 579:1332-1337

Shohael AM, Ali MB, Yu KW, Hahn EJ, Islam R, Paek KY (2006) Effect of light on oxidative stress, secondary metabolites and induction of antioxidant enzymes in Eleutherococcus senticosus somatic embryos in bioreactor. Process Biochem 41:1179-1185

Showalter AM, Varner JE (1987) Plant hydroxyproline-rich glycoproteins. In: Marcus A (ed) The biochemistry of plants. A comprehensive treatise. Academic Press, San Diego, pp 485-520

Teissié J, Golzio M, Rols MP (2005) Mechanisms of cell membrane electropermeabilization: a minireview or our present (lack of?) knowledge. Biochem Biophys Acta 1724:270-280

Vayda ME, Schaeffer HJ (1988) Hypoxic stress inhibits the appearance of wound-response proteins in potato tubers. Plant Physiol 88:805-809

von Wirén N, Klair S, Bansal S, Briat JF, Khodr H, Shioiri T, Leigh RA, Hider RC (1999) Nicotianamine chelates both Fe $\mathrm{Fe}^{\mathrm{III}}$ and Fe $\mathrm{Fe}^{\mathrm{II}}$. Implications for metal transport in plants. Plant Physiol 119:1107-1114

Weaver JC (1993) Electroporation: a general phenomenon for manipulating cells and tissues. J Cell Biochem 51:426-435

Weaver JC (2000) Electroporation of cells and tissues. IEEE Trans Plasma Sci 28:24-33

Wishart DS (2008) Metabolomics: applications to food science and nutrition research. Trends Food Sci Tech 19:393-482

Yang WL, Bernards MA (2007) Metabolite profiling of potato (Solanum tuberosum L.) tubers during wound-induced suberization. Metabolomics 3:147-159

Ye H, Huang LL, Chen SD, Zhong JJ (2004) Pulsed electric fields stimulates plant secondary metabolism in suspension cultures of Taxus chinensis. Biotech Bioeng 88:788-795 